\title{
Using Surveys to Measure 'Value Added' in Skills in Four Faculties
}

\section{J. PAUL GRAYSON}

Institute for Social Research, York University.

\section{ABSTRACT}

Some universities in Canada and other countries are interested in knowing the value-added to skills - e.g., critical and communication skills - by the university experience. The best way of obtaining information on this matter is through longitudinal analyses with appropriate control groups that utilize both subjective and objective measures of skills; unfortunately, such designs are costly and studies based on them take a long time to complete. In this article an alternate strategy that involved comparing the skills of entering and graduating students at York University is described. It is argued that information collected in this fashion can be of assistance in assessing the value added to specific skills and can be used in a diagnostic fashion by faculties concerned with skills development.

\section{RÉSUMÉ}

Certaines universités au Canada et dans d'autres pays sont intéressées à connaître les compétences à «valeur ajoutée», par exemple, les compétences analystiques et communicatives, que l'enseignement supérieur permet aux étudiants d'acquérir. Pour obtenir des renseignements à ce sujet, la meilleure façon est de faire des analyses longitudinales à l'aide des groupes de contrôle appropriés en utilisant des 
méthodes subjectives et objectives. Malheuresment, de tels projets sont toujours coûteux et les études qui s'y rapportent prennent beaucoup de temps. Dans cet article, aune autre stratégie de comparaison de compétences entre les étudiants qui entrent à l'Université York et ceux qui en sortent est exposée en détail. On constate que l'information recueillie de cette manière peut être utilisée pour l'évaluation des compétences à «valeur ajoutée»ainsi que pour l'analyse de l'acquisition de ces compétences par les facultés qui s'y intéressent.

\section{INTRODUCTION}

An increasing number of Canadian universities are carrying out surveys of their graduates that among other things ask students to comment on development in various skills, such as analytic and communication skills, over the course of their education. To date, however, few if any attempts have been made to measure the value added to skills by the university experience. There are several reasons for this. First, there is no consensus regarding skills that should be developed over the course of a student's university career. Second, even if agreement were reached on which skills should be developed, there is no agreement on ways to measure them. Third, the longitudinal studies required to measure value added in skills are expensive and take a long time to complete. At York University, in order to measure the value added in skills over the course of an undergraduate education, steps were taken to deal with each of the three problems. First, an iterative process was established in which members of the university community identified skills that, ideally, would be improved over the course of a university education. Second, survey questions were developed to measure such skills on the part of students entering, and graduating from, four faculties. Third, a research design was used in which skills of entering students were compared to those of graduating students after adjustments had been made through an analysis of covariance for Ontario Academic Credit marks, gender, ethno-racial origin, and language spoken in the home while growing up. This article focuses on the rationale for conducting an analysis of the value added to skills in this relatively cost effective fashion and the results of the research. 


\section{BACKGROUND TO RESEARCH}

In a review of exit surveys used in Canadian universities, Evers and O'Hara (1996) define knowledge as, "The understanding of a body of information in a particular field; for example, electrical engineering." Skills are seen as, "The abilities or proficiencies developed in certain areas; for example, written communication." Finally, values are defined as, "The commonly held positive attitudes toward an abstract concept; for example, respect for diversity" (p. 44).

Evers and O'Hara note that while a growing number of Canadian universities use self-reports in exit surveys to measure their graduates' knowledge, skills, and values (KSV), "there is little evidence of the development of more sophisticated methodologies such as behavioural measures or objective testing of KSV" (p. 54). In addition to devising such measures, like many other researchers, particularly in the United States, they conclude that it is necessary to develop indicators of the value added by the institution to students' knowledge, skills, and values. This objective can only be achieved if information is collected on both entering and graduating students.

There are a number of steps that must be taken if these desiderata are to be achieved. First, to focus only on skills, it is necessary to develop agreement regarding the types of skills that should be fostered during an undergraduate career. As attempts to achieve this objective at the national level have been less than successful in the United States (Jones, 1994; Pike, 1995a), it is highly unlikely that we will have any more luck north of the border. As a result, it makes sense for individual universities to decide for themselves the skills with which they are most concerned. If this can be done in conjunction with other universities, so much the better.

Once individual institutions reach some form of agreement on which skills should be developed, the second step is to find ways to measure them. In the cross-sectional exit surveys examined by Evers and O'Hara, students are typically asked to self-report on how much university experiences have increased skills, such as communication or interpersonal skills.

As well as using self-reports to measure skills, standardized tests, such as the California Critical Thinking Skills Test, the Watson-Glaser Critical Thinking Appraisal, the Ennis Weir Thinking Essay Test, and the Cornell Critical Thinking Test, can be used to measure skills; 
however, in many instances users must pay to utilize instruments such as these. Moreover, incentives must frequently be given to students to complete lengthy test modules. For example, Pascarella and Associates (1995) report that in their longitudinal study of university outcomes in the United States they started by paying students $\$ 25$ U.S. to complete tests and questionnaires and that the stipend increased by $\$ 5$ each time additional tests were taken. Even if standardized tests are used, questions can be raised regarding their validity, particularly for measuring shortterm gains in skills (Jacobs, 1995; McMillan, 1987).

Independent of whether or not self-reports in surveys or standardized tests are used to measure skills, when examining how much students' experiences in any given university contribute to the development of skills or any other desired outcome, it is important to obtain measures of the outcome under consideration at entry and again at graduation so that the value added can be assessed (Astin, 1991). Similar measures should be taken of a same-age control group that does not attend university. Increases in skills between entering and graduating students that are not also observed in the control group can be attributed to the university experience.

In longitudinal research such as this, because many students might leave the university or refuse to participate in both the entry and exit measurement of skills, large samples are required to ensure that at graduation sufficient numbers are still involved in the study to facilitate meaningful analysis. Even if a large sample remains at graduation the possibility exists that non-participants are different from students who remain in the study. In addition, control group attrition is a potential problem. Also, when relying on longitudinal studies, institutions must wait until a cohort has made its way through the university system before a measure of value added is available.

\section{A COST EFFECTIVE ALTERNATIVE}

Clearly, identifying and measuring skills, and determining the value added by the university experience to skills in a longitudinal study is a complicated, potentially costly, and time consuming process. There is, however, a way to decrease the cost and amount of time needed to obtain information on the value added component of the university experience. Subject to qualifications regarding question wording to be discussed later, this approach involves using surveys in which entering and graduating students provide self-assessments of skills in particular 
areas. Through an analysis of covariance, after controlling for variables having the potential to influence skills acquisition, such as previous levels of achievement (high school marks), gender, language spoken in the home, and ethno-racial origin, comparisons between the groups can then be made on various measures of skills. If comparisons show that graduating students have skills not evident among entering students and a same-age control group, differences between the entering and graduating students can be attributed to the university experience. Variations of this method have been used successfully by Keeley, Browne and Kreutzer (1982) and Steele (1986).

One problem with this approach is that when they entered university, the graduating students may have been different from the entering group with whom they are being compared. For example, if in recent years an increased emphasis had been placed on certain skills in high schools, entering students would demonstrate higher levels of skills than would have been displayed by graduating students when they were in first year. A second problem is that students with certain characteristics, low motivation for example, may leave the university before completing their studies. As a result, graduating students may be different from those entering the university in ways that are hard to detect and control. Despite these potential difficulties, Pascarella and Terenzini (1991) point out that in studies carried out on reflective judgment, longitudinal and cross-sectional research produce similar results. A similar conclusion was reached by Pace (1979). As a result, provided that adjustments are made for possible confounding influences, cross-sectional studies involving entering and graduating students can be used by institutions in assessing the valued added in particular skills.

Although both longitudinal and cross-sectional studies require an external control group if the possible effects of the university experience are to be disentangled from those of maturation, external control groups are most often absent from studies of university outcomes. While this presents difficulties if the intent is to assess the effect of the university experience per se, provided same-age groups are under consideration, it is less problematic if the research objective is one of assessing the impact of different institutional contexts on outcomes. For example, if the outcomes of one university, faculty, or department are being compared with those of other universities, faculties, or departments, provided that same-age groups are involved in the study and that pre-entry characteristics are held constant, an external control group is not required. 


\section{SELF-REPORTS}

Self-reports are an integral part of the relatively more cost and time effective response to measuring valued added in generic skills currently under discussion; however, some may view the use of techniques such as this as less desirable than more objective measures of skills. As Pike (1995a) points out, however, in the United States, the National Education Goals Panel Resources Group on Adult Literacy and Lifelong Learning noted that the development of assessment tools of use at the national level to measure university outcomes would cost several million dollars and take many years to complete. In the interim the Group recommended that self-reports be used as proxies.

To what extent can self-reports be viewed as reasonable proxies of knowledge and/or skills, and/or values? After examining a number of studies in which the results of self-reports were compared to test results, Pascarella and Terenzini (1991) conclude that correlations between selfreports and other measures of the same phenomena range from .25 to .65 . More importantly, the literature they draw upon in their examination indicates that the validity of self-reports varies with the specific knowledge and/or skills, and/or values under discussion. For example, Berdie (1971) found a high correlation between self-professed knowledge of public figures and the results of tests designed to measure knowledge of the same figures; however, the relationships between selfreported and tested knowledge of authors and artists were not as high. Similarly, Pohlmann and Beggs (1974) discovered that self-reports of academic growth in the affective realm were supported by test results. Growth in simple and complex cognitive realms, however, did not correlate highly with self-reports. In a review of the literature on the utility of self-reports, Baird (1976) cites examples of both high and low relationships with external measures of various phenomena. Still others have presented information suggesting that while self-reports have some uses, they should not be viewed as substitutes for other measures of various college or university outcomes (Dumont \& Troelstrup, 1980; McMorris \& Ambrosino, 1973). Overall, despite their limitations and inconsistencies in the research, Kuh and Associates (1997) report that self-reports are valid when:respondents know the information requested; questions are clear and unambiguous; and respondents treat questions seriously. 
In a study conducted by Pike (1995a) conclusions were reached that support the validity of the second condition of Kuh and Associates. Briefly, Pike studied 1,568 graduating students from ten colleges and universities in the United States who completed the College Basic Academic Subjects Examination (College BASE) adapted for graduating students. The College BASE tests proficiency in English, mathematics, science, and social science. Students who completed the examination also participated in a survey in which they rated their ability on exactly the same matters covered in the examination. The correlations between test performance and self-reports were sufficiently high for Pike to conclude that self-reports can be used as general proxies for traditional measures of academic achievement. Nonetheless, in an earlier publication Pike (1995b) noted that self-reports were good proxies for proficiency in mathematics, reasonably weak proxies for English and science competency, and very weak indicators of proficiency in social studies.

As a general rule Pike emphasizes that if self-reports are to be valid measures of, in his case, knowledge measured in standardized tests, there must be a high content correspondence between the self-report questions and those asked in tests. (While this may seem self-evident, other research has focused on the relationship between some general self-report measures and the results of specific tests.) If this rule is not followed, it may be difficult to specify exactly what self-reports measure.

Although this and other work by Pike (1994, 1995b) is encouraging, it should be stressed that the focus of his research has been on knowledge (not skills) as measured through the College BASE. Although research to be analysed in this report assumes a similar relationship between self-reported skills and the results of tests designed to measure such skills, research is necessary to confirm the connection.

An encouraging step in this direction has been taken by Evers and Associates (1993) in a study in which they compared the self-reported skill levels of recent graduates of a number of Canadian universities to assessments of the same skills by their employers. The average correlation for statistically significant relationships between self-reports and employers' assessments was .16. The correlation was highest for written communication skills, .26, and lowest for decision making skills, .07 .

An examination of data derived from The International Adult Literacy Survey (IALS) (Anonymous, 1995) jointly undertaken by Statistics Canada and The Educational Testing Service located in the 
United States, also sheds light on the relationship between self-reported and other measures of skills. As well as obtaining self-assessments of reading, writing, and quantitative skills, this study required participants to complete a number of performance tasks of varying levels of difficulty related to prose literacy, document literacy, and quantitative literacy. For Canadians aged 16 to 25 who had completed postsecondary education (the group most comparable to the subjects of the current study) the correlations between self-assessed reading and test measured prose and document literacy were .45 and .36 respectively. The correlations between self-reported writing skill and test measured prose and document literacy were .29 and .22 ; however, the last mentioned was not statistically significant. Finally, there was a correlation of .29 between self-assessed quantitative skills and quantitative literacy as measured in tests.

The study by Evers and Associates and the results of the IALS survey indicate on the basis of Canadian data that there do appear to be statistically significant correlations between self-assessments of skills and skills measured in other ways. While the magnitude of these correlations is insufficient for making academic decisions about, for example, individual university graduates who may be presumed to have mastered this or that skill, they are sufficient for analyses of differences in skill development among graduates of different departments or universities.

\section{THE IMPORTANT SKILLS}

Although there have been some attempts in Canada to identify the skills that university graduates should acquire (Conference Board of Canada, 1992; Evers \& Rush, 1996), there has been no general acceptance of the results of these endeavors. Consequently, in this study, a list of desirable skills was developed through an inductive process that could be utilized easily in other universities. In an iterative process, faculty members with knowledge of skills development, along with researchers from the Institute for Social Research at York University, identified a number of tasks, the performance of which ideally would be improved over the course of a university career. ${ }^{\prime}$ Next, questions were developed that focused on the difficulty students would have in completing specific tasks. Finally, questions were grouped into logical categories. Although in the IALS study reasonable correlations were found between some general questions on skills and test measured skills, in keeping with 
Pike's finding noted earlier, tasks, and their related questions, were very specific and relevant to students' experiences.

Survey questions were tested in a small pilot survey involving students about to graduate from Pure and Applied Science, Arts, Fine Arts, and Administrative Studies. For each question, on a five point scale, responses of 1 indicated a high, and 5 a low, level of difficulty in completing the specific task referenced in the question. On the basis of the pilot, some questions were dropped and assessments were made of the reliability of indices comprised of various questions. The relevant skill categories and question topics used in the construction of indices are displayed in Table 1 .

\section{THE SAMPLE}

Information for the analysis of value added in generic skills between first year and graduation was collected in two surveys conducted in the Fall of 1995 and one in the Spring of 1996. In one of the Fall 1995 surveys, questionnaires assessing skills were mailed to all students who had just entered the faculties of Fine Arts, Science, and Administrative Studies and to a sample of students entering the Faculty of Arts. The numbers of returns were $171,223,100$, and 812 respectively. The response rate was $55 \%$.

The second survey carried out in the Fall of 1995 focused on all students eligible to graduate in the Fall convocation. In total, 480 Arts students returned completed questionnaires as did 25, 30, and 6 students from the Faculties of Fine Arts, Science, and Administrative Studies respectively. Low numbers reflect the facts that compared to Arts other faculties are small and relatively few students graduate in the Fall. The response rate for the survey was $58 \%$.

The survey carried out in the Spring and early summer of 1996 included all students from the same faculties eligible to graduate in the June convocation. In total, 1,835 Arts graduates, 180 graduates from Fine Arts, 165 from Science, and 70 graduates from the Schulich School of Business completed the survey for a response rate of $51 \%$. Overall, the three surveys included 1,306 entering and 2,791 graduating students. The results of all three surveys were merged together and with information, such as grades, obtained from administrative records. 


\section{Table 1}

\section{Skill Categories and Question Topics}

\section{Analytic Skills}

- identifying the main points in lectures in your major

- clearly identifying the pros and cons of controversial issues like abortion

- figuring out the main arguments in articles written on topics in your discipline

- identifying flaws in positions given by other students in classes or seminars

- explaining your strengths and weaknesses to a potential employer

- defending a position you have taken in a classroom or seminar against the criticisms of other students

\section{Communication Skills}

- taking an article you read for a course this year and summarizing it in no more than two pages

- verbally presenting your ideas on a topic of your choice to a group of ten strangers

- verbally communicating to other students in your classes the flaws in their positions or arguments

- writing a letter to a friend

- writing a letter of application for a job

- expressing yourself clearly in written English in an essay

- correcting the grammar and spelling in the essay of a friend

\section{Personal Skills}

- assessing the feelings of people you have worked with in part-time or summer jobs

- 'cooling out' a friend who is annoyed with you

- being able to apologize to someone if you said something wrong about them

- being able to admit to yourself when you are wrong

- being able to get along with other people

- enjoying meeting new people

- helping friends patch up disagreements

- considering the feelings of others

- knowing yourself

\section{Organizational Skills}

- planning a job search strategy for a friend

- organizing priorities to prevent rushing at the last minute

- recruiting and organizing twenty strangers to collect money for the Heart and Stroke Fund 
Table 1 (continued)

\section{Comparative Skills}

- comparing what is going on in Canada to what is going on in a third world country

- comparing what is going on in Canada today to what was going on fifty years ago

- comparing what is going on in Canada to what is going on in any European country

\section{Basic Numeracy Skills}

- determining change from a $\$ 10$ bill for a $\$ 2.75$ pen

- calculating $15 \%$ discount on a $\$ 9.36$ book

- determining percentage Liberal vote when 15 students vote Conservative, 10 NDP, and 20 Liberal

- solving $x$ in the equation: $3 x-5=56.7$

- explaining the meaning of 'square root"

\section{Basic Computer Skills}

- using a word processing program

- using a spread sheet program

- using a statistical analysis program

The characteristics of survey respondents are summarized in Table 2. Consistent with the sampling procedures outlined above, for both the entering and graduating surveys, the vast majority of students were enrolled in the Faculty of Arts. For both surveys nearly two thirds of respondents were female. Administrative records indicate that this gender distribution is comparable to that for undergraduate students as a whole. With regard to ethno-racial origin, the majority of both entering and graduating students identify themselves as of European origin; however, there are more students of European origin among graduating than entering students. Finally, most students in both surveys spoke English in the home while growing up. Nonetheless, considerably more graduates than entrants reported English as their home language. 
Table 2

\section{Characteristics of Survey Respondents}

\begin{tabular}{|c|c|c|c|c|}
\hline & & Entrants & Graduates & $\begin{array}{c}\text { Group } \\
\text { Total }\end{array}$ \\
\hline \multirow[t]{4}{*}{ Faculty } & Business & $\begin{array}{r}7.7 \% \\
104\end{array}$ & $\begin{array}{r}3.1 \% \\
70\end{array}$ & $\begin{array}{r}4.8 \% \\
174\end{array}$ \\
\hline & Arts & $\begin{array}{r}61.7 \% \\
839\end{array}$ & $\begin{array}{r}81.6 \% \\
1835\end{array}$ & $\begin{array}{r}74.1 \% \\
2674\end{array}$ \\
\hline & Fine Arts & $\begin{array}{r}13.3 \% \\
181\end{array}$ & $\begin{array}{r}8.0 \% \\
180\end{array}$ & $\begin{array}{r}10.0 \% \\
361\end{array}$ \\
\hline & Science & $\begin{array}{r}17.3 \% \\
235\end{array}$ & $\begin{array}{r}7.3 \% \\
165\end{array}$ & $\begin{array}{r}11.1 \% \\
400\end{array}$ \\
\hline \multirow[t]{2}{*}{ Group Total } & $\mathrm{Col} \%$ & $100.0 \%$ & $100.0 \%$ & $100.0 \%$ \\
\hline & Count & 1359 & 2250 & 3609 \\
\hline \multirow[t]{2}{*}{ Gender } & Female & $\begin{array}{r}61.0 \% \\
831\end{array}$ & $\begin{array}{r}68.0 \% \\
1531\end{array}$ & $\begin{array}{r}65.4 \% \\
2362\end{array}$ \\
\hline & Male & $\begin{array}{r}39.0 \% \\
531\end{array}$ & $\begin{array}{r}32.0 \% \\
719\end{array}$ & $\begin{array}{r}34.6 \% \\
1250\end{array}$ \\
\hline \multirow[t]{2}{*}{ Group Total } & $\mathrm{Col} \%$ & $100.0 \%$ & $100.0 \%$ & $100.0 \%$ \\
\hline & Count & 1362 & 2250 & 3612 \\
\hline \multirow[t]{5}{*}{$\begin{array}{l}\text { Ethno-Racial } \\
\text { Origin }\end{array}$} & Black & $\begin{array}{r}5.3 \% \\
72\end{array}$ & $\begin{array}{r}6.1 \% \\
135\end{array}$ & $\begin{array}{r}5.8 \% \\
207\end{array}$ \\
\hline & South Asian & $\begin{array}{r}8.0 \% \\
108\end{array}$ & $\begin{array}{r}4.2 \% \\
94\end{array}$ & $\begin{array}{r}5.6 \% \\
202\end{array}$ \\
\hline & Chinese & $\begin{array}{r}16.6 \% \\
225\end{array}$ & $\begin{array}{r}5.7 \% \\
128\end{array}$ & $\begin{array}{r}9.9 \% \\
353\end{array}$ \\
\hline & Other & $\begin{array}{r}14.8 \% \\
200\end{array}$ & $\begin{array}{r}10.6 \% \\
235\end{array}$ & $\begin{array}{r}12.1 \% \\
435\end{array}$ \\
\hline & European & $\begin{array}{r}55.3 \% \\
749\end{array}$ & $\begin{array}{r}73.4 \% \\
1635\end{array}$ & $\begin{array}{r}66.6 \% \\
2384\end{array}$ \\
\hline \multirow[t]{2}{*}{ Group Total } & $\mathrm{Col} \%$ & $100.0 \%$ & $100.0 \%$ & $100.0 \%$ \\
\hline & Count & 1354 & 2227 & 3581 \\
\hline
\end{tabular}


Table 2 (continued)

\begin{tabular}{|c|c|c|c|c|}
\hline & & Entrants & Graduates & $\begin{array}{c}\text { Group } \\
\text { Total }\end{array}$ \\
\hline \multirow[t]{4}{*}{$\begin{array}{l}\text { Home } \\
\text { Language }\end{array}$} & English & $\begin{array}{r}63.9 \% \\
868\end{array}$ & $\begin{array}{r}76.4 \% \\
1722\end{array}$ & $\begin{array}{r}71.7 \% \\
2590\end{array}$ \\
\hline & Chinese & $\begin{array}{r}12.8 \% \\
174\end{array}$ & $\begin{array}{r}3.0 \% \\
67\end{array}$ & $\begin{array}{r}6.7 \% \\
241\end{array}$ \\
\hline & Italian & $\begin{array}{r}3.5 \% \\
48\end{array}$ & $\begin{array}{r}6.4 \% \\
144\end{array}$ & $\begin{array}{r}5.3 \% \\
192\end{array}$ \\
\hline & Other & $\begin{array}{r}19.7 \% \\
268\end{array}$ & $\begin{array}{r}14.2 \% \\
320\end{array}$ & $\begin{array}{r}16.3 \% \\
588\end{array}$ \\
\hline \multirow[t]{2}{*}{ Group Total } & $\mathrm{Col} \%$ & $100.0 \%$ & $100.0 \%$ & $100.0 \%$ \\
\hline & Count & 1358 & 2253 & 3611 \\
\hline
\end{tabular}

\section{CONTROL GROUPS}

While it is not possible to have an external control group for the current study, a means of estimating the extent to which maturation affected the skills under examination was devised. This objective was accomplished by using the responses to 6,974 questionnaires completed for departmental reviews in the Winter and Spring of 1996 and 1997 (response rate approximately 65\%). Among other things, at the departmental level, such surveys measure the same skills as in the survey of entering and graduating students.

In brief, the logic of the procedure for estimating the effects of maturation is based on the fact that in all faculties but one at York University, most students enter first year from high school. The exception is Atkinson College, the evening operation at York, that caters to mature students, most of whom are older than traditional students in other undergraduate faculties. While the vast majority of students entering Atkinson have some prior postsecondary education, a minority have, at best, completed high school. As a result, differences in skill levels between students entering Atkinson with no more than high school education, and traditional entrants to other faculties, can be attributed to the maturation process. 
Unfortunately, as with most of the research focussing on value added by the university experience, resources did not permit the establishment of an external control group. Even if resources had not been an issue, given how some of the specific skill constellations under discussion were operationalized, it is doubtful that a comparison with an external control group would have been meaningful. For example, being able to identify the main points in lectures in your major is irrelevant to someone with no postsecondary experience. Moreover, as the objective is to measure the value added in skills among graduates of various faculties, a control group is not necessary.

\section{RELIABILITY OF INDICES}

The reliability of the various indices of skills as outlined in Table 1 was tested in the combined surveys of graduating and entering students by using Cronbach's alpha which:

. . can be viewed as the correlation between this test or scale and all other possible tests or scales containing the same number of items, which could be constructed from a hypothetical universe of items that measure the characteristic of interest.

(Norusis, 1992, p. 149)

In general, indices having alphas at or above .7 can be regarded as reliable.

With one exception, alphas were well above .7. The coefficient for analytical skills was .84; for communication skills .80; personal skills had a coefficient of .81 ; for comparative skills the alpha was .85 ; the coefficient for basic numeracy skills was .79; and for basic computer skills alpha was .78 . Only organizing skills, with a coefficient of .63 , must be treated with caution. ${ }^{2}$

\section{CORRELATIONS AMONG SKILLS AND GRADES}

Correlations among each of the skills and Ontario Academic Credit (OAC) marks are reported in Tables 3 and 4. The first thing of note is that for entering students (Table 3) correlations between OAC marks and various skills are low. Of those that are statistically significant, there is a positive correlation between, on the one hand, OACs and, on the other, communication skills (.102), organizing skills (.076), numeracy skills (.101), and basic computer skills (.065); however, for personal skills the 


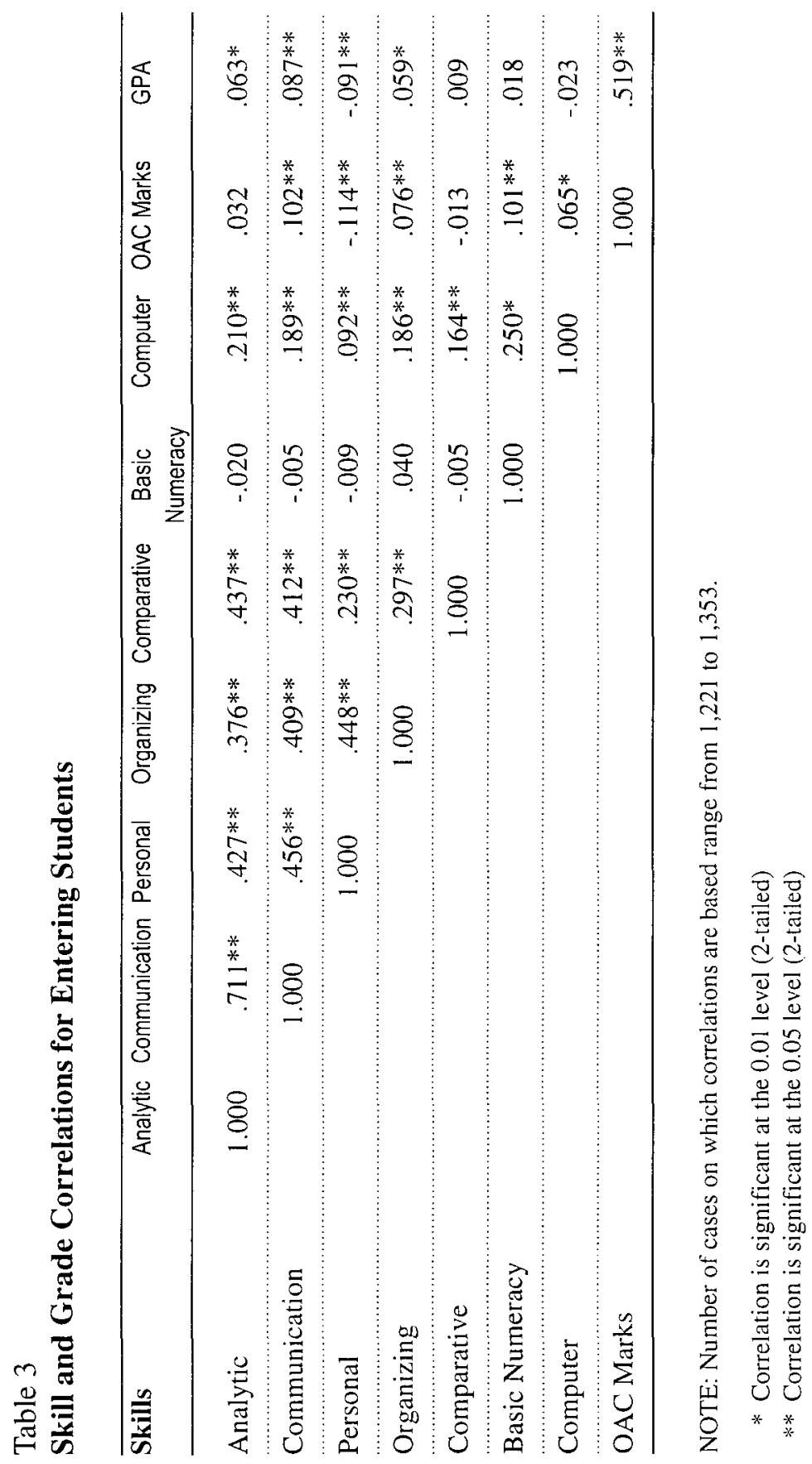




\begin{tabular}{|c|c|c|c|c|c|c|c|c|c|}
\hline Skills & Analytic & Communication & Personal & Organizing & Comparative & $\begin{array}{c}\text { Basic } \\
\text { Numeracy }\end{array}$ & Computer & OAC Marks & GPA \\
\hline Analytic & 1.000 & $.700 * *$ & $.454 * *$ & $.454 * *$ & $.428 * *$ & $.154^{* *}$ & $.169 * *$ & $.065^{* *}$ & $.151 * *$ \\
\hline Personal & & & 1.000 & $.496^{* *}$ & $.303 * *$ & $.127 * *$ & $.102 * *$ & -.042 & $-.044 *$ \\
\hline Organizing & & & & 1.000 & $.361^{* *}$ & $.095^{* *}$ & $.200 * *$ & .018 & .041 \\
\hline Comparative & & & & & 1.000 & $.127 * *$ & $.187 * *$ & $-.058 *$ & $-.045^{*}$ \\
\hline Basic Numeracy & & & & & & 1.000 & $.315 * *$ & $.100 * *$ & $.055^{*}$ \\
\hline
\end{tabular}

NOTE: Number of cases on which correlations are based range from 1,641 to 2,250.

* Correlation is significant at the 0.01 level (2-tailed)

** Correlation is significant at the 0.05 level (2-tailed) 
correlation is negative (-.114). If first year GPA is examined, it is evident that the highest statistically significant correlations is with OAC marks (.519). Statistically significant correlations of GPA with skills are weak. Analytic, communication, and organizing skills have correlations of $.063, .087$, and .059 with first year GPA. Personal skills correlate negatively (-.091) with GPA.

There are two ways in which these general finding can be interpreted. First, if one expects that generic skills examined here are a necessary condition for high school achievement as measured in OAC marks, the low correlations can be taken as an indication that the current measures of generic skills are invalid: students with high OAC marks must possess high generic skills. On the other hand, if it can be accepted that OAC marks do not necessarily reflect generic skills the findings make sense. Certainly many faculty who bemoan the lack of preparation on the part of first year students despite high OAC marks would be amenable to this interpretation. At the same time, if employers are to be believed, it is equally likely that there is little relationship between high university grades and skills (Jones, 1994).

Unfortunately, support for employers concerns is found in Table 4. For graduating students there are statistically significant, but weak, correlations (.151 and .193 respectively) between analytical and communication skills and cumulative grade point average (GPA). Smaller yet statistically significant correlations of .055 and .082 are found between basic numeracy and basic computer skills and GPA. Correlations between personal and comparative skills ( -.044 and -.045 respectively) are small and negative, but statistically significant. In essence, there is at best a weak relationship between some skills and cumulative GPA of graduating students: marks may measure subject knowledge, but not skills.

Unfortunately, once again, we are left with a quandary. If we assume that university graduates must possess the generic skills analysed here, then we must also conclude that the skill measures employed in the study are invalid. If, on the other hand, we accept the views of critics that university curricula do not necessarily instill skills and that grades do not also measure skills, the findings help validate the skills measures employed in the study. As some other researchers (Franklin, 1995; Money, 1996) have also reported weak relationships between measures of various skills and grades, it is tempting to side with employers. 
While the link between skills and GPA may be weak, in Table 4, the correlation between cumulative GPA and OAC marks is a statistically significant .636. This relationship is comparable to the findings of studies of graduating students in the United States (Astin, 1993). In essence, OAC marks maintain a reasonably strong relationship with academic achievement over the students' university careers. Indeed, the correlation of OACs with cumulative GPAs of graduating students is higher than the correlation with first year grade point averages. This observation may be explained by the probability that students with low GPAs are less likely than others to finish their education.

\section{CONTROL VARIABLES}

In the analysis of net gains in various skills, it is important to control for possible confounding variables such as gender, racial origin, and language spoken in the home while the student was growing up. That each may have implications for particular skills is evident from Tables 5, 6, and 7 that include unstandardized and unadjusted skills scores and grades for entering and graduating students combined.

Unfortunately, space constraints prevent a detailed examination of data in the tables. At every general level, however, it is obvious that considerable differences in skills are associated with differences in gender, racial origin, and home language. For example, from Table 5 it is seen that males score highest on basic numeracy, and computer skills. Females do better than males on analytic, personal, and organizational skills. There are no statistically significant differences for comparative skills.

If ethno-racial origin as summarized in Table 6 is examined, black students score highest on analytic and communication skills. Students of European origin have the highest scores on personal and organizing skills while South Asian origin and other students do best on comparative skills and South Asian origin students score highest on computer skills. The highest scores on basic numeracy skills are reported by students of Chinese origin. It must be stressed that absolute differences among some scores for different ethno-racial groups are very low.

One cause for alarm is the low rating for students of Chinese origin on analytic, communication, and comparative skills. As the majority of these students did not speak English in their homes, these figures likely illustrate the impact of language on various skills areas. In a relatively 


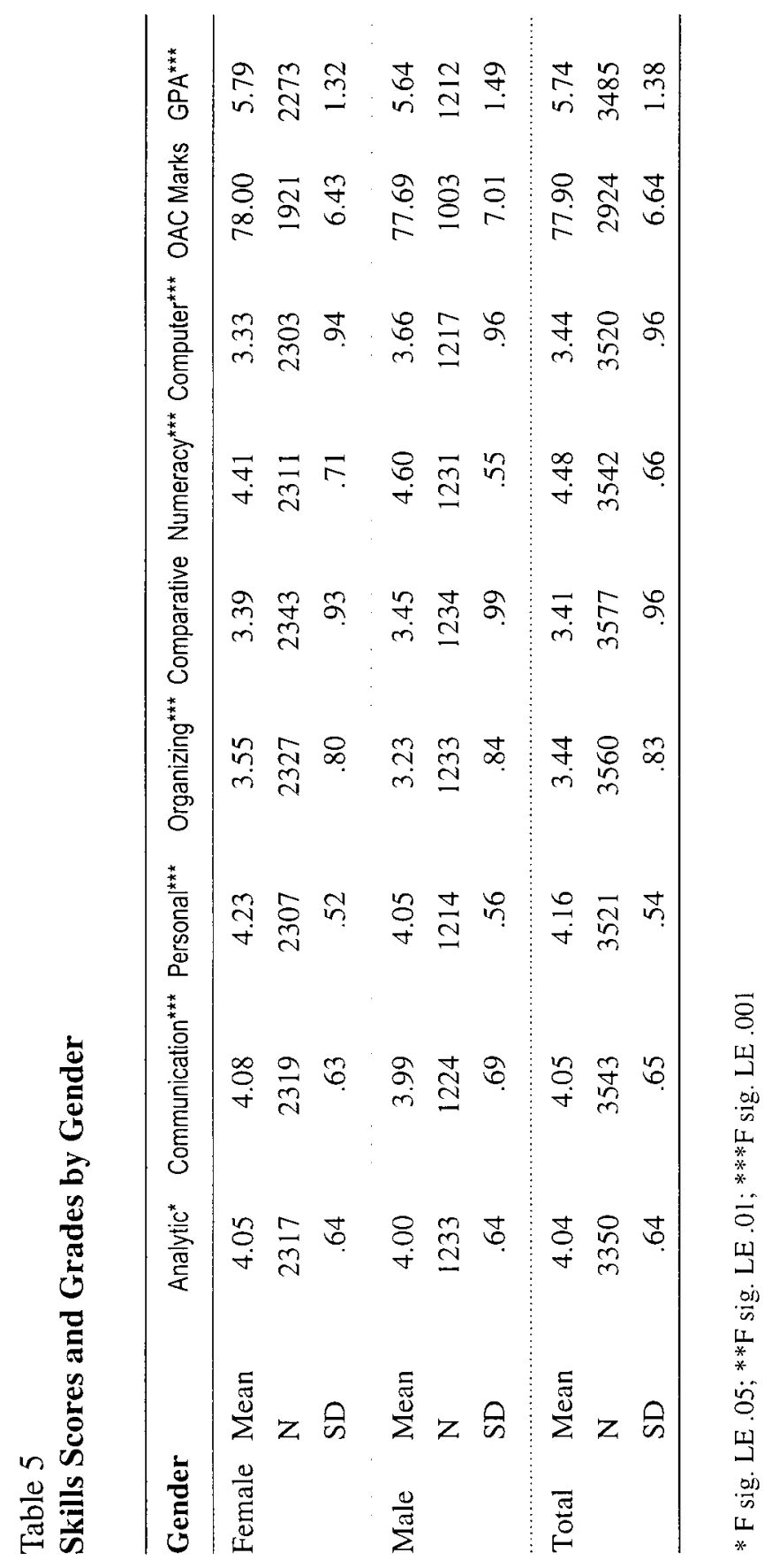

The Canadian Journal of Higher Education Volume XXXX, No. 1, 1999 


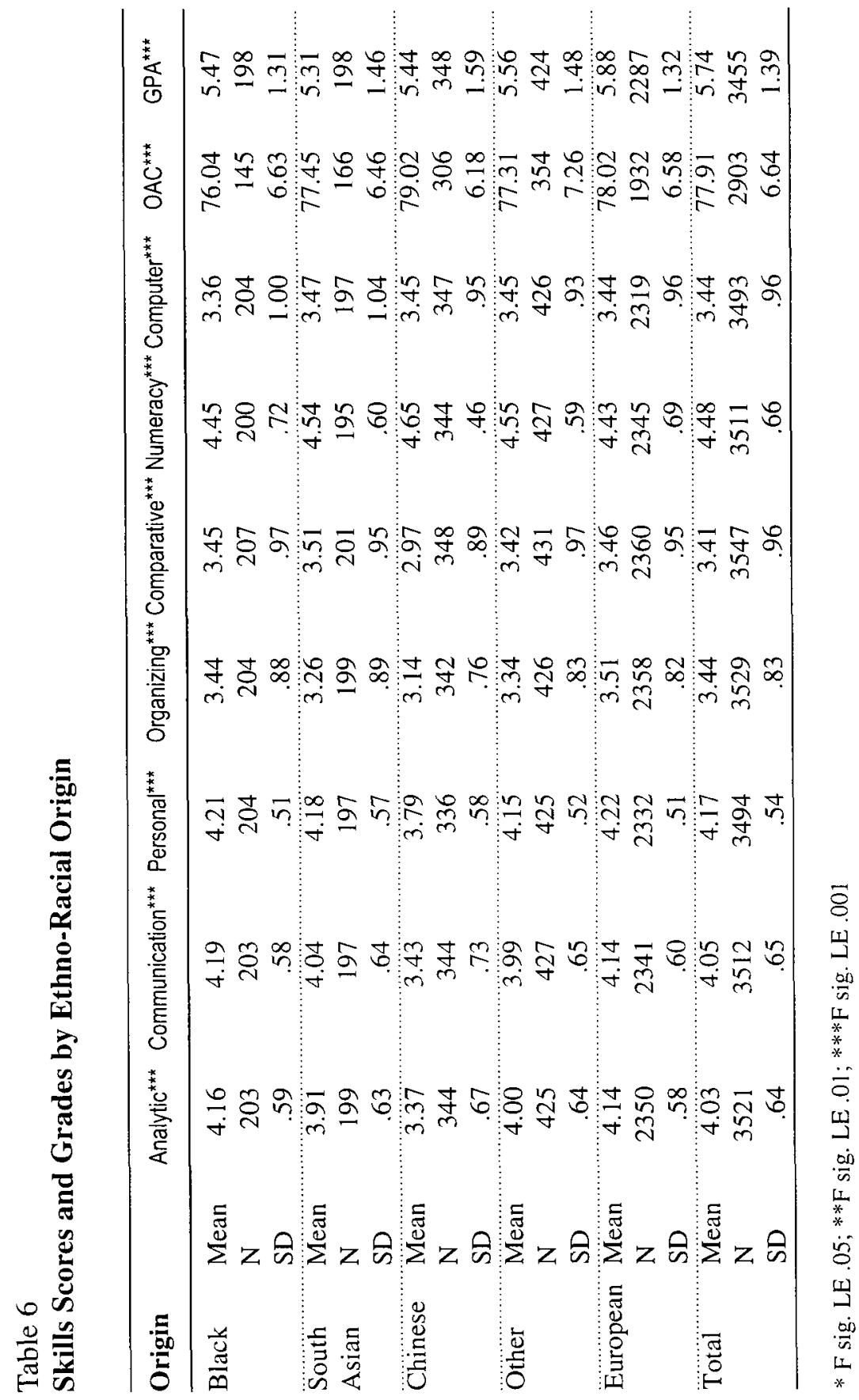

The Canadian Journal of Higher Education

Volume XXXX, No. 1, 1999 


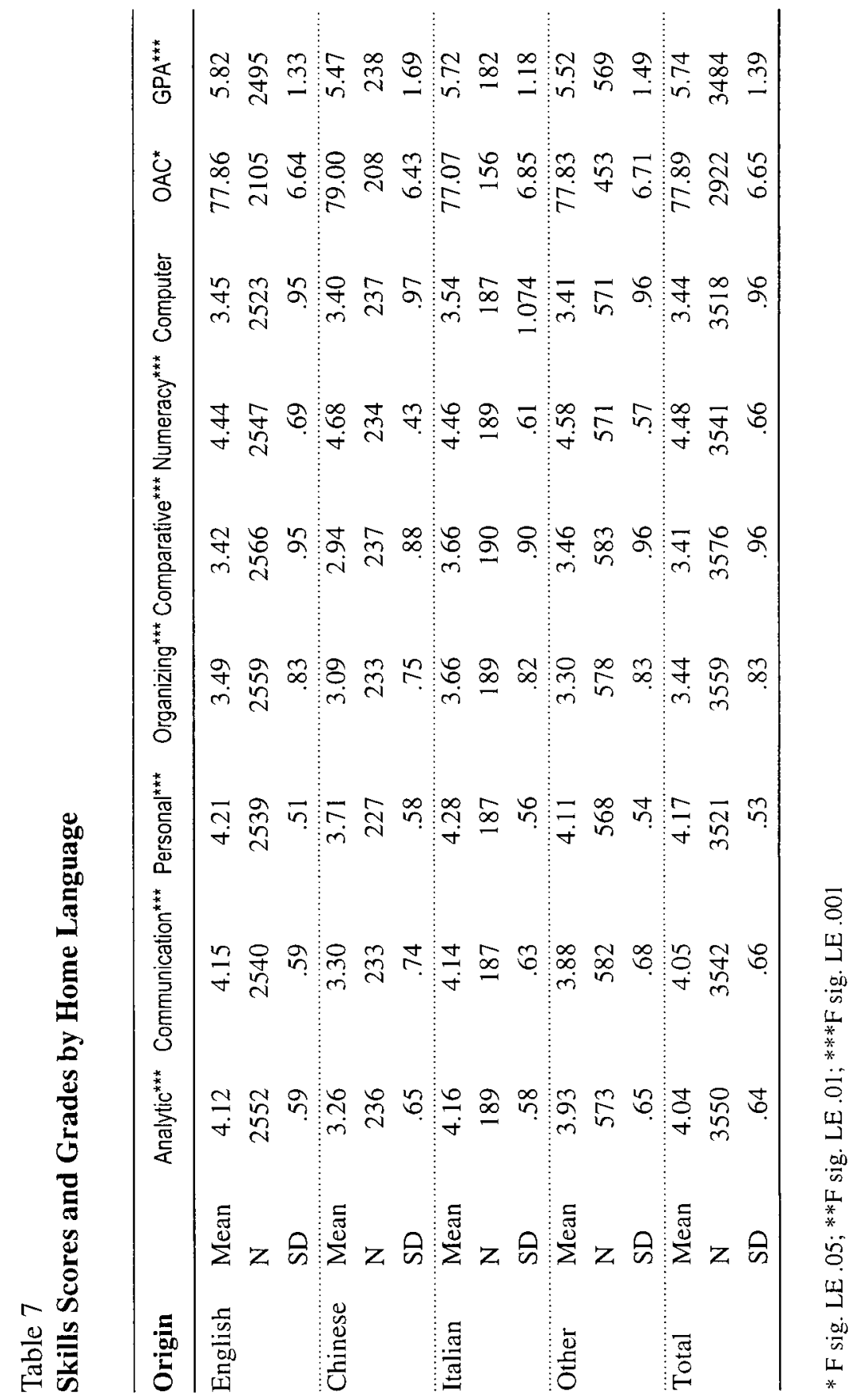

The Canadian Journal of Higher Education

Volume XXIX, No. 1, 1999 
language neutral area, like basic numeracy, students of Chinese origin score high.

The importance of language is further illustrated when language spoken in the home is examined. Table 7 shows that students who spoke Italian while growing up score highest in analytic, personal, organizing, comparative, and computer skills. Students who spoke English do best in communication skills. Finally, students who grew up speaking Chinese have the highest scores in basic numeracy.

\section{ASSESSING VALUE ADDED}

As noted earlier, in order to determine value added, it is necessary to compare the scores on various skill indices of graduating to entering students. While standardized scores are not necessary to achieve this objective, there were two reasons for calculating them in the current undertaking. (For most practical purposes standardized scores, or z-scores, have a mean of 0 and a standard deviation of 1.) First, in order to compare changes at York to changes reported in the literature, and to make changes understandable to the average reader, it is necessary to specify differences between graduating and entering students in terms of percentile point differences. Second, standardized rather than actual scores will be reported in order to protect the confidentiality of the York data. In essence, while readers will know the amount of change that can be attributed to the university experience, they will not know the absolute value of entering and graduating scores (however, such data are available to the York community). From a value added perspective the former information is more important than the latter: the concern is not with the level of skills of graduating students but with how much the university experience has contributed to the development of skills.

Percentile point difference in the skills of graduating as compared to entering students in the Schulich School of Business (Business), Arts, Fine Arts, and Pure and Applied Science (Science), after adjusting for OAC marks, gender, ethno-racial origin, and home language, are presented in Table 8. The specific skills analysed are listed in column one. Column two, Entering Students, lists standardized scores for each skill by faculty for students entering the university. Similar measures for graduating students are found in column three, Graduating Students. For columns two and three the number of cases on which the scores are calculated are found 
Table 8

Skills' Z-scores by Faculty for Entering and Graduating Students (Controls on OAC marks, gender, ethno-racial origin and home language)

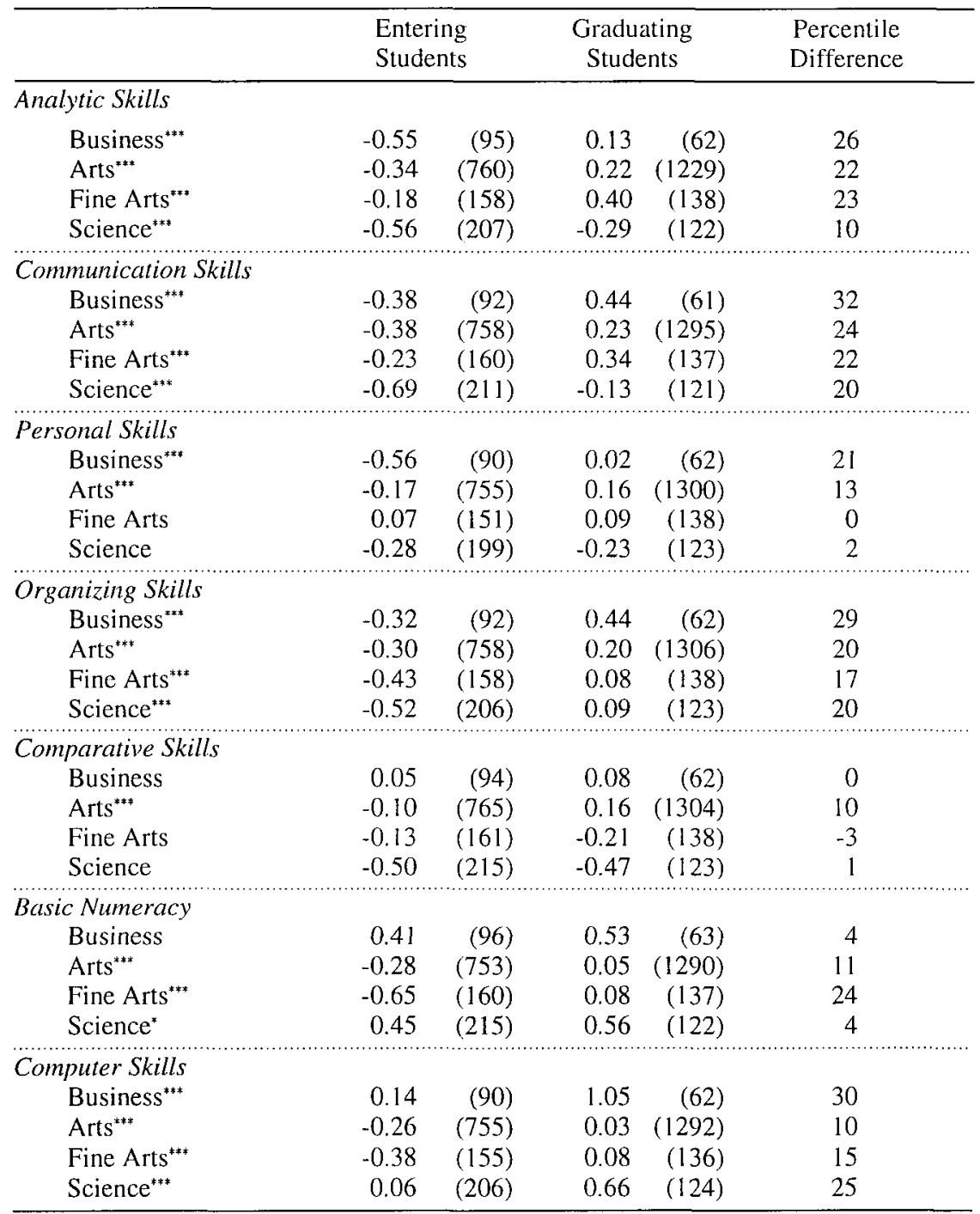

Significance for $\mathrm{F}$ for differences between entering and graduating students:

* LE .05; ** LE .01; *** LE .001

Number of cases in parenthesis. 
in parenthesis. In column four, differences in scores for entering and graduating students are presented as percentile point differences.

To begin with analytic skills, the highest scores for entering students are found among students entering Fine Arts (-.18) and Arts (-.34). Among graduating students, those from Fine Arts (.40) and Arts (.22) have the highest scores. In terms of the difference between the scores of entering and graduating students, however, the greatest improvement, or value added, is observed for Business students ( 26 percentile points).

With communication skills, students entering Fine Arts have the highest scores (-.23) and Science students the lowest (-.69). Among graduating students those from Business have the highest scores (.44). Moreover, the value added in communication skills (32 percentile points) is higher once again in Business than in any other faculty.

Students entering Fine Arts report the highest scores on personal skills (.07). Among graduates the highest scores are for Arts students (.16). In terms of value added, however, Business students show the greatest improvement ( 21 percentile points).

Among entering students, those going into Arts have the highest organizing scores (-.30); however, among graduates, those from Business score highest (.44). Business students also show the greatest value added (29 percentile points).

When it comes to comparative skills, entering Business students do better than others (.05). Upon graduation, however, Arts students score highest (.16). Arts students also display the greatest value added (10 percentile points). It is worth noting that for Fine Arts students there is a net loss in terms of comparative skills between first and final year $(-3$ percentile points). As it is unlikely that a Fine Arts curriculum relates to comparative skills as measured here, this is not surprising.

With scores of .45 , students entering Science have the highest basic numeracy scores among first year students. Science students also have the highest scores among graduating students (.56). In terms of value added, however, the greatest improvement is found for Fine Arts graduates ( 24 percentile points). It should be noted, however, that the final Fine Arts score is only .08.

Among entering students, those in Business have the highest scores on basic computer literacy (.14). This score increases to 1.05 for Business graduates and represents a gain of 30 percentile points, the highest increase of students in any faculty. 
There are two ways in which the data in Table 8 can be examined. First, it can arbitrarily be decided that for graduating students a score of, say, .10 is too low in an absolute sense for any skills under discussion. If this yardstick is accepted, the scores of graduating Science students for analytic (-.29), communication (-.13), personal (-.23), organizing (.09), and comparative skills $(-.47)$ are unacceptable. Similarly, the personal (.02) and comparative (.08) scores of Business graduates are problematic. The problem areas for Fine Arts graduates are personal skills (.09), organizing skills (.08), comparative skills $(-.21)$, basic numeracy skills (.08), and computer skills (.08). Arts students are low in the areas of basic numeracy (.05) and computer skills (.03).

The second way in which the data can be examined is in terms of value added. If this tack is followed, it can be seen that the greatest gains in analytic, communication, personal, organizing, and computer skills are made by students in Business. The value added in comparative skills is greatest for Arts graduates and Fine Arts students show the greatest increases in basic numeracy.

Overall, the information in Table 8 indicates first, that some skill levels of graduating students in certain faculties are too low. Second, faculties differ in the amount of value added to particular generic skills.

In order to obtain an overview of value added in the skills under discussion, we can simply take the average over the four faculties. When this is done, in descending order average gains are: communication skills (25 percentile points), organizing skills ( 22 percentile points), analytic and computer skills (20 percentile points each), basic numeracy skills (11 percentile points), personal skills ( 9 percentile points), and comparative skills ( 2 percentile points).

\section{THE EFFECTS OF MATURATION}

As noted earlier, it was not possible to have an external same age control group of individuals who did not go to university. As a result, there is a possibility that the skills gains noted in the previous section could be totally or in part a result of maturation. In order to test for this possibility, using the results of surveys carried out for departmental reviews, the skill scores of first year students in Atkinson College were compared to those of students in other undergraduate faculties. The average age of first year Atkinson students was 32 ; in other faculties it was 21 . The mean number 
of courses registered in or completed for Atkinson students was .8; for other students, 4.4 .

The analysis was restricted to first year students who had no prior postsecondary education at either the college or university level and skill scores were adjusted for the effects of gender, ethno-racial origin, and language spoken in the home while growing up. Adjustments were not made for OAC marks because admission to Atkinson is not necessarily based on high school performance.

The results of analyses of covariance indicate that with one exception there were no statistically significant differences between first year students in Atkinson and in other faculties or colleges on the measures of skill used in this study. The exception was organizing skills for which the mean score of Atkinson students was 11 percentile points higher than scores of other students. Findings such as these give support to the notion that differences between entering and graduating students analysed earlier are not simply the result of maturation.

This said, a note of caution must be sounded. Surveys for program reviews are carried out between January and March. As a result, it is possible (but not probable) that the skills of students in colleges or faculties other than Atkinson could have differentially increased since the beginning of the year.

\section{AN OVERALL ASSESSMENT}

How can we evaluate the differences in generic skill scores of students entering and leaving York University? Fortunately, in their tome, How College Affects Students, Pascarella and Terenzini (1991) have summarized findings from a number of studies on freshman to senior gains in a number of domains similar to those analysed here (see Table 9).

The first column of the table lists the skills under consideration. Column two lists the effect size that can be viewed as the difference between the mean score for graduating and entering students divided by the entering student standard deviation. This value is equivalent to the unadjusted mean in the analysis of covariance conducted for this report. Elsewhere (Grayson, 1996) it has been shown that for the Faculty of Arts at York, differences between unadjusted and adjusted means for the skills scores are minor. Column three contains information on effect size translated into area under the normal curve. 
Table 9

Summary of Estimated Freshman-to-Senior Changes: Learning and Cognitive Development

\begin{tabular}{lcc}
\hline Outcome & $\begin{array}{c}\text { Effect Size } \\
\text { General verbal skills }\end{array}$ & $\begin{array}{c}\text { Percentile Point } \\
\text { Difference }\end{array}$ \\
General quantitative skills & .56 & 21 \\
Specific subject matter knowledge & .84 & 10 \\
Oral communication skills & .60 & 31 \\
Written communication skills & .50 & 22 \\
Piagetian (formal) reasoning & .33 & 19 \\
Critical thinking & 1.00 & 34 \\
Use of reason and evidence to address & & 34 \\
ill-structured problems (reflective judgment, & & 38 \\
informal reasoning) & 1.00 & 13 \\
Ability to deal with conceptual complexity & 1.20 & \\
\hline
\end{tabular}

Taken from Pascarella \& Terenzini (1991), p. 558.

There are two important observations that can be made on the basis of the data in Table 9. First, overall gains between first and final year are modest ranging from a low of 10 percentile points for quantitative skills to a high of 38 percentile points for ability to deal with conceptual complexity. Second, while different measurement techniques preclude direct comparisons, there is enough similarity between differences observed at York and those seen in studies conducted elsewhere to inspire confidence in measures used for the York study.

For example, Pascarella and Terenzini report gains of 21 percentile points for general verbal skills, 22 points in oral communication skills, and 19 percentile points in written communication skills (the average for these three is 21 percentile points). At York, average gains in communication 
skills, that included some general verbal as well as written and oral components, were 24 percentile points. The same is true of quantitative skills: Pascarella and Terenzini report gains of 10 percentile points and the average gain in basic numeracy at York was 11 percentile points.

It must be stressed that the studies summarized by Pascarella and Terenzini used many different measures of the skills under consideration (some involved the use of standardized tests of various skills). As a result, it would be wrong to place too much emphasis on specific comparisons between their and the York findings. What is important is the fact that on the two gains on which it was possible to comment, increases observed at York were similar in size to those measured elsewhere.

\section{BROADER IMPLICATIONS}

Students graduating from four faculties at York University report higher skills than entering students. Unfortunately, the degree to which value added in generic skills at York is comparable to that in other Canadian universities is contingent upon the latter opening comparable avenues of inquiry and publicizing the results.

In the event that similar research were initiated, what might be expected? Research carried out in the United States can be of assistance in answering this question. As Pascarella and Terenzini (1991), after their review of approximately 3,000 U.S. studies related to university outcomes, argue:

There are clear and unmistakable differences among postsecondary institutions in a wide variety of areas, including size and complexity, control, mission, financial and educational resources, the scholarly productivity of faculty, reputation and prestige, and the characteristics of the students enrolled. At the same time, however, American colleges and universities also resemble one another in a number of important respects. It may be that despite their structural and organization differences, their similarities in curricular content, structures, and sequencing; instructional practices; overall educational goals; faculty values; out-of-class experiences; and other areas do in fact produce essentially similar effects on students although the 'start' and 'end' points may be very different across institutions. (p. 589) 
Given that U.S. universities are far more diverse than those in Canada, it is likely that in this country there is even a smaller difference in outcomes such as those studied here than south of the border. In other words, while institutions like York, Memorial, Queen's, Ryerson Polytechnic University, the University of Toronto, Western, the University of Manitoba, the University of Regina, and the University of Victoria may vary in things like resources and the entering average of students, based on findings from U.S. research, it is unlikely that great differences exist in the value added to skills similar to those studied at York.

\section{CONCLUSION}

The objective of this study was to assess the value added to generic skills by the university experience. In the best of all possible worlds such a study would have measured the skill levels of entering students using both self-reports and standardized tests and then, after the students had completed their education, skills measured with the same instruments could be compared to those at entry. Provided that increases in skills were not also observed in a same age control group that did not attend university differences between entry and exiting skill levels could be attributed to the university experience.

Unfortunately, this type of research is both costly and time consuming and unlikely to be carried out in Canadian universities; however, the type of research described in this report, in which, after adjusting for potentially confounding influences, self-reports of skill levels of entering students were compared to those of graduating students, is a cost effec- . tive and timely alternative to collecting information in longitudinal studies. The justification for taking this tack can be found in previous research indicating acceptable levels of agreement between self-assessed and other measures of skills and the similarity in results of cross-sectional and longitudinal research carried out in related areas. Although information collected via the process described in this study should not be used in decisions regarding individuals, it does have utility in assessing change in groups.

Information collected in this fashion can have several practical applications. First, once benchmarks have been established, within institutions, individual faculties can determine whether or not relative to other faculties their students emerge from their courses of studies with acceptable skill levels. Second, faculties that make deliberate attempts to 
enhance certain skills can see if there are differences in skill levels between entering and graduating students. In either the first or second cases, if skill levels are lower than desired, steps can be taken to remedy the problem. Third, if similar information were available from other institutions, universities could compare the value added by their institution to that of other universities. Once again, if comparisons were unfavourable, changes could be introduced to deal with deficiencies.

Consistent with the foregoing possibilities, the most important finding of the current study was that, in keeping with previous research, students graduate from York with better developed skills than students who enter the institution. There are, however, important differences between and among faculties in terms of the value added to particular skills and in some faculties the skill scores of graduating students may be too low. Moreover, some evidence suggests that the differences observed between entering and graduating students are not the result of maturation. Furthermore, the magnitude of two average gains in skills are comparable to gains recorded in the United States. Given the results of research conducted south of the border, similarity in results such as these is to be expected. Unfortunately, we will not be able to compare the value added at York to that of other Canadian universities until the latter conduct the required research.

\section{References}

Anonymous (1995). Literacy, economy and society: results of the first international adult literacy survey. Ottawa, ON: OECD \& Statistics Canada. Astin, A. (1991). Assessment for excellence. Toronto, ON: Collier Macmillan. Astin, A. (1993). What matters in college? San Francisco, CA: Jossey Bass.

Baird, L. (1976) Using self-reports to predict student performance. New York, NY: College Entrance Examination Board.

Berdie, R. (1971). Self-claimed and tested knowledge. Educational and Psychological Measurement, 31(3), 629-636.

Conference Board of Canada. (1992). Employability skills profile. Ottawa, ON.

Dumont, R., \& Troelstrup, R. (1980) Exploring relationships between objective and subjective measures of instructional outcomes. Research in Higher Education, 12(1), 37-51.

Evers, F., Rush, J., Krmpotic, J., \& Duncan-Robinson, J. (1993). Making the match: Phase II. Guelph, ON: University of Guelph. 
Evers, F., \& O'Hara, S. (1996). Educational outcome measures of knowledge, skills, and values. Education Quarterly Review, 3(1), 43-56.

Evers, F., \& Rush, J. (1996). The bases of competence: Skill development during the transaction from university to work. Management Learning, 27(3), 275-299.

Franklin, M. (1995). The effects of differential college environments on academic learning and student perceptions of cognitive development. Research in Higher Education, 36(2), 127-153.

Grayson, J. (1995). Does race matter? - Outcomes of the first year experience in a Canadian university. The Canadian Journal of Higher Education, 25(2), 79-109.

Grayson, J. (1996). Value added in generic skills between first and final year: a pilot project. Toronto, ON: Institute for Social Research, York University.

Jacobs, S. (1995). Technical characteristics and some correlates of the California critical thinking skills test, forms A and B. Research in Higher Education, 36(1), 89-108.

Jones, E. (1994) Essential skills in writing, speech and listening, and critical thinking for college graduates: perspectives of faculty, employers, and policy makers. National Centre on Postsecondary Teaching, Learning, and Assessment.

Keeley, S., Browne, M., \& Kreutzer, J. (1982) A comparison of freshmen and seniors in general and specific essay tests of critical thinking. Research in Higher Education, I7(2), 139-154.

Kuh, G., Vesper, N., Connolly, M., \& Pace, R. (1997). College student experiences questionnaire: Revised norms for the third edition. Bloomington, IN: Center for Postsecondary Research and Planning, Indiana University.

McMillan, J. (1987). Enhancing college students' critical thinking: a review of studies. Research in Higher Education, 26(1), 3-29.

McMorris, R., \& Ambrosino, R. (1973). Self-report predictors: A reminder. Journal of Educational Measurement, 10(1), 13-17.

Money, S. (1996). The relationship between critical thinking scores, achievement scores, and grade point average in three different disciplines. Ph.D. dissertation draft, Michigan State University.

Norusis, M. (1992). SPSS for Windows: Professional Statistics. Chicago, IL: SPSS.

Pace, C. (1979). Measuring outcomes of college. San Francisco, CA: Jossey Bass.

Pascarella, E., \& Terenzini, P. (1991). How college affects students. San Francisco, CA: Jossey Bass.

Pascarella, E., Bohr, L., Amaury, N., \& Terenzini, P. (1995). Intercollegiate athletic participation and freshman year cognitive outcomes. The Journal of Higher Education, 66(4), 369-387. 
Pascarella, E., Nora, A., \& Bohr, L. (n.d.). Longitudinal panel study instruments and documents. National Center on Teaching, Learning, and Assessment.

Pike, G. (1995a). Limitations of using students' self-reports of academic development as proxies for traditional achievement measures. Paper presented to the Annual Meeting of the Association for Institutional Research, Boston, MA.

Pike, G. (1995b). The relationship between self-reports of college experiences and achievement test scores. Research in Higher Education, 36(1), 1-21.

Pike, G. (1994). The relationship between self-report and objective measures of student achievement. Paper presented to the Annual Meeting of the Association for the Study of Higher Education, Tucson, AZ.

Pohlmann, J., \& Beggs, D. (1974). A study of the validity of self-reported measures of academic growth. Journal of Educational Measurement, 2(2), 1 15-120.

Spector, P. (1992). Summated rating scale construction. Newbury Park, CA: Sage Publications.

Steele, J. (1986). Assessing reasoning and communication skills of postsecondary students. Paper presented to the meeting of the American Educational Research Association, San Francisco, CA.

\section{Notes}

1 Ron Sheese, Nick Elson, Darla Rhyne, Tammy Chi, David Northrup, and Paul Grayson participated in this phase of the study.

2 For November 1995 graduates of the Faculty of Arts, a principal component analysis using all of the skills variables was conducted in which the number of factors specified for retention, 7 , was equal to the number of indices that had been constructed. With factor loadings lower than .4 suppressed, the analysis yielded factors similar to those of basic numeracy, computer skills, personal skills, comparative skills, and job procuring skills. The other factors combined, in no systematic fashion, variables that comprised the analytical and communication skill categories (see Spector [1992] for a rationale). On the basis of these findings, it was deemed appropriate to retain the original indices. 